\title{
Amniotic membrane transplantation in acute chemical burns
}

\begin{abstract}
Purpose To evaluate the outcome of fresh amniotic membrane transplantation (AMT) for ocular surface reconstruction in acute chemical burns.

Methods A prospective study of 15 consecutive eyes with acute chemical burns was performed. In all, 10 eyes had lime burns and five eyes had acid burns. There were three eyes of grade II, four eyes of grade III and eight eyes of grade IV burns. AMT was performed within 3 weeks of injury.

Results Patients were followed up for $10.14 \pm 4.41$ months. All patients had immediate relief of pain postoperatively. Of 15 eyes, nine $(60 \%)$ showed epithelialization within $1-4$ weeks $(15.33 \pm 9.91$ days $)$. The final visual acuity improved in 10 of 15 eyes $(66.66 \%)$. Eyes with burns of grade II and III showed more visual improvement than those with grade IV burns. None of the eyes showed perforation. Symblepharon was seen in nine of 15 eyes (60\%). Of 15 eyes, $12(80 \%)$ experienced limbal stem cell deficiency and showed superficial corneal vascularization. Conclusions Amniotic membrane transplantation with fresh amniotic membrane increases patient comfort and reduces inflammation. In mild burns, AMT alone restores corneal and conjunctival surfaces. In moderate to severe burns, it probably reduces conjunctival scarring sequelae, but does not prevent the sequelae of limbal stem cell deficiency that requires further limbal stem cell transplantation. In the acute stage, amniotic membrane transplantation probably has a protective role against the progressive melting and perforation. Eye (2005) 19, 273-278. doi:10.1038/sj.eye.6701490 Published online 30 July 2004
\end{abstract}

Keywords: amniotic membrane transplantation; chemical burns; limbal stem cell deficiency;

R Arora, D Mehta and $\mathrm{V}$ Jain

persistent epithelial defect; limbal stem cell transplantation

\section{Introduction}

Chemical injuries of the eye produce extensive damage to the ocular surface epithelium, cornea, anterior segment, and limbal stem cells resulting in permanent unilateral or bilateral visual impairment. Damage to limbal stem cell results in corneal conjunctivalization, vascularization, chronic inflammation, and recurrent or persistent epithelial defects. Severe damage to conjunctival cells causes mucus deficiency and persistent subconjunctival inflammation resulting in severe dry eye and fibrosis of subconjunctival tissue. The successful management of chemical burns demands reducing the severity of damage to both limbal stem cells and conjunctival cells besides reducing inflammation and preventing progressive tissue melting.

Medical treatment for acute ocular burns includes topical and systemic ascorbate, ${ }^{1}$ citrate ${ }^{2}$ tetracycline, ${ }^{3}$ and steroids. ${ }^{4}$ Application of glued on-hard contact lens, ${ }^{5}$ tenoplasty, ${ }^{6}$ use of tissue adhesives, ${ }^{7}$ and large-diameter keratoplasty ${ }^{8}$ are some of the surgical procedures tried in the management of severe ocular burns.

Recently, there have been several reports of successful treatment of acute ocular burns using amniotic membrane transplantation. Meller et $a l^{9}$ reported that AMT alone was sufficient to restore corneal and conjunctival surface in mild to moderate burns. In severe burns, it restored the conjunctival surface without symblepharon and reduced limbal stromal inflammation but did not prevent limbal stem cell deficiency that required further limbal stem cell transplantation. However, Dua et al ${ }^{10}$ reported failure of AMT to restore ocular surface or
Cornea Services Guru Nanak Eye Center New Delhi 110002 India

Correspondence:

R Arora

D-1, Nizammudin West New Delhi 110013 India

Tel.: +911124351415

E-mail: aroraj@ del3.vsnl.net.in

Received: 29 August 2003 Accepted: 29 December 2003

Published online: 30 July 2004 
preserve the integrity of eye in severe acute burns. A recent report by Kobayashi et al also emphasized that immediate amniotic membrane transplantation is useful for mild to moderate acute chemical burns and preserves ocular surface integrity. ${ }^{11}$

In the current study, we report our experience with the use of nonpreserved amniotic membrane for the treatment of acute ocular chemical burns.

\section{Materials and methods}

From February 2002 to February 2003, amniotic membrane transplantation was performed in a prospective manner on 15 eyes of 14 consecutive patients with acute chemical burns. The age ranged between $6-53$ years. The male: female ratio was 10:4 with a mean age of $20.60 \pm 11.93$ years for the males and $16.25 \pm 8.42$ years for females. In all, 10 eyes had lime burns and five eyes had acid burns. A total of 13 eyes had accidental injuries and two eyes of the same patient had injury due to vitriolage. The severity was classified as grade II in three eyes, Grade III in four eyes and Grade IV in eight eyes based on the criteria defined by the Roper-Hall. ${ }^{12}$ Of the eight eyes in grade IV burns, five eyes had total limbal ischaemia $(2,3,9,11,12)$. A total of five eyes had conjunctival ischaemia between 75 and $100 \%$. Lime deposits on conjunctiva were seen in six eyes of the total nine eyes with lime burns. In case 1 , lime particles were present in addition intrastromally in the cornea. All eyes had epithelial defect at presentation. The demographic data and clinical characteristics are summerized in Tables 1 and 2.

All patients received a detailed ophthalmic examination, including visual acuity, slit lamp, tonometry, and fundus examination (wherever possible). The Schirmer test with and without anaesthesia was used to evaluate tear function. A detailed assessment of limbal ischaemia and conjunctival involvement in the form of necrosis, lime deposits, and ischaemia was made. Cases with lid involvement were excluded from the study.

All the patients were initially treated with medical therapies consisting of copious saline irrigation, topical antibiotics, lubricants, cycloplegics, $10 \%$ citrate, $10 \%$ ascorbate, and systemic vitamin C ( $2 \mathrm{~g} /$ day $)$. All patients had persistent inflammation, epithelial breakdown and limbal ischaemia without any progress at presentation, before amniotic membrane transplantation (AMT). AMT was performed within 3 weeks after injury. Informed consent was obtained after explanation of the procedure being undertaken.

Nonpreserved fresh human amniotic membrane was used in all the patients. Amniotic membrane was

Table 1 Clinical and demographic data of patients

\begin{tabular}{|c|c|c|c|c|c|c|}
\hline $\begin{array}{l}\text { Patient } \\
\text { no. }\end{array}$ & Age/sex & Agent/eye & Grade & Key findings & $\begin{array}{l}\text { Time b/w injury } \\
\text { and surgery }\end{array}$ & Extent of $A M T$ \\
\hline 1 & $26 / \mathrm{F}$ & Lime/OD & IV & $\begin{array}{l}\text { LI: } 8 \mathrm{cl} . \mathrm{hrs} ; \mathrm{J}: 50 \% \text {; C: } 100 \% \mathrm{ED} \text {, } \\
\text { intrastromal + forniceal lime deposits }\end{array}$ & 12 & Circular patch \\
\hline 2 & $19 / \mathrm{F}$ & Acid/OD & IV & $\begin{array}{l}\text { LI: } 12 \text { cl.hrs; J: } 100 \% \text {; total conj necrosis, } \\
\text { C: } 100 \% \text { ED, Cat }\end{array}$ & 6 & Lid to lid \\
\hline 3 & $19 / \mathrm{F}$ & Acid/OS & IV & $\begin{array}{l}\text { LI: } 12 \text { cl.hrs; J: } 100 \% \text {; total conj. Necrosis, } \\
\text { C: } 100 \% \text { ED, Cat }\end{array}$ & 6 & Lid to lid \\
\hline 4 & $14 / \mathrm{F}$ & Lime/OS & II & $\begin{array}{l}\text { LI: } 3 \text { cl.hrs; J: } 50 \% \text {; SN + inf. forn. } \\
\text { necrosis with lime deposits, C: } 100 \% \text { ED }\end{array}$ & 3 & Lid to lid \\
\hline 5 & $10 / \mathrm{M}$ & Lime/OD & III & $\begin{array}{l}\text { LI: } 6 \text { cl.hrs; J: 25\%; with lime deposits, C: } \\
\text { 100\% ED }\end{array}$ & 16 & Lid to lid \\
\hline 6 & $6 / \mathrm{F}$ & Lime/OD & IV & $\begin{array}{l}\text { LI: } 8 \text { cl.hrs; J: } 80 \% \text {; sup. forn. conj } \\
\text { necrosis + lime deposits, C: } 100 \% \text { ED }\end{array}$ & 14 & Lid to lid \\
\hline 7 & $19 / \mathrm{M}$ & Lime/OS & III & LI: 4 cl.hrs; J: 25\%; C: $80 \%$ ED & 6 & Circular patch \\
\hline 8 & $15 / \mathrm{M}$ & Acid/OS & II & LI: 4 cl.hrs; J: 25\%; C: $80 \%$ ED & 7 & Circular patch \\
\hline 9 & $12 / \mathrm{M}$ & Lime/OD & IV & $\begin{array}{l}\text { LI: } 12 \text { cl.hrs; J: 100\%; Sup forn. conj. } \\
\text { necrosis + lime deposits; C: } 100 \% \text { ED }\end{array}$ & 10 & Lid to lid \\
\hline 10 & $18 / \mathrm{M}$ & Cement/OS & IV & LI: 7 cl.hrs; J: 25\%, C: 100\% ED & 12 & Lid to lid \\
\hline 11 & $19 / \mathrm{M}$ & Lime/OS & IV & $\begin{array}{l}\text { LI: } 12 \text { cl.hrs; J: 50\%; sup conj. necrosis } \\
\text { and ass lime deposits, C: } 100 \% \text { ED }\end{array}$ & 12 & Lid to lid \\
\hline 12 & $53 / \mathrm{M}$ & Acid/OD & IV & $\begin{array}{l}\text { LI: } 12 \text { cl.hrs; J: } 75 \% \text {; sup + inf conj. } \\
\text { necrosis, C: } 80 \% \text { ED, Cat }\end{array}$ & 7 & Lid to lid \\
\hline 13 & $19 / \mathrm{M}$ & Lime/OD & III & LI: 4 cl.hrs; J: 25\%; C: 100\% ED & 12 & Lid to lid \\
\hline 14 & $20 / \mathrm{M}$ & Acid/OS & III & LI: 6 cl.hrs; J: 50\%; C: 80\% ED & 14 & Circular patch \\
\hline 15 & $21 / \mathrm{M}$ & Lime/OS & II & LI: 1 cl.hrs; J: 25\%; C: 50\%ED & 12 & Circular patch \\
\hline
\end{tabular}

AMT, amniotic membrane transplantation; OD, right eye; OS, left eye; LI, limbal ischemia; J, conjunctiva; C, cornea; ED, epithelial defect; cl.hrs, clock hours; cat, cataract; b/w, between; inf, inferior; conj, conjunctiva; forn, fornix. 
Table 2 Clinical data

\begin{tabular}{|c|c|c|c|c|c|}
\hline \multirow[t]{2}{*}{ Patient no. } & \multicolumn{2}{|c|}{ Visual acuity } & \multirow[t]{2}{*}{ ED Healing } & \multirow[t]{2}{*}{ Symblepharon/Vascularization (cl.hrs) } & \multirow[t]{2}{*}{ Follow-up (months) } \\
\hline & Before & After & & & \\
\hline 1 & $1 / 60$ & FCCF & 4 months & $+/+(8)$ & 15 \\
\hline 2 & PR accurate & PR inaccurate & 4 months & $+/+(12)$ & 15 \\
\hline 3 & $1 / 60$ & PR accurate & 4 months & $+/+(12)$ & 15 \\
\hline 4 & $6 / 36$ & $6 / 6$ & 14 days & $+/-$ & 15 \\
\hline 5 & $1 / 60$ & $6 / 18$ & 21 days & $-/+(3)$ & 11 \\
\hline 6 & $1 / 60$ & $1 / 60$ & 24 days & $+/+(10)$ & 11 \\
\hline 7 & $6 / 24$ & $6 / 9$ & 7 days & $-/-$ & 10 \\
\hline 8 & $6 / 36$ & $6 / 6$ & 8 days & $-/-$ & 9 \\
\hline 9 & PR accurate & $6 / 36$ & 2.5 months & $+/+(12)$ & 8 \\
\hline 10 & FCCF & $6 / 60$ & 4 months & $-/+(12)$ & 5 \\
\hline 11 & FCCF & $3 / 60$ & 18 days & $+/+(12)$ & 5 \\
\hline 12 & FCCF & FCCF & 18 days & $+/+(8)$ & 4 \\
\hline 13 & FCCF & $6 / 60$ & 2 months & $-/+(6)$ & 4 \\
\hline 14 & FCCF & $6 / 9$ & 21 days & $+/+(3)$ & 15 \\
\hline 15 & $1 / 60$ & $6 / 60$ & 7 days & $-/+(2)$ & 15 \\
\hline
\end{tabular}

FCCF, finger counting close to face; cl.hrs, clock hours; PR, projection of rays.

obtained from women undergoing elective caesarean section who were seronegative for hepatitis $B$, hepatitis $\mathrm{C}$, syphilis and human immunodeficiency virus before surgery. The advantage of fresh human amniotic membrane being its relatively easy availability, though, there remains the disadvantage of lack of serological donor tests 3 months after preparation. Membranes were manually separated from the underlying placental tissue and rinsed in $0.9 \%$ normal saline four times to wash away blood and foetal tissues and once in $0.025 \%$ sodium hypochlorite. The amnion along with the underlying chorion was cut up into pieces measuring $5 \times 5 \mathrm{~cm}^{2}$ in size and stored in normal saline containing $50,000 \mathrm{U}$ of penicillin and $1 \mathrm{~g}$ of streptomycin per $400 \mathrm{ml}$ of saline, stored at $4 \mathrm{C}$ not exceeding a period of $48 \mathrm{~h}$. At the time of surgery, the amnion was dissected bluntly from the chorion, and washed thoroughly in normal saline containing gentamicin prior to use. In six eyes $(1,5,7,8,14,15)$, amniotic membrane was used as a circular patch covering the cornea and limbus and sutured to the less damaged conjunctival surface (so that the damaged area was covered). In the remaining nine eyes, amniotic membrane covered the whole ocular surface from lid margin to lid margin. Amniotic membrane was spread on the surface of eye stromal side down, a symblepharon ring of appropriate size was fitted over it. Edges of amniotic membrane after trimming were sutured to lid margins with $8 / 0$ vicryl. Bandage contact lens was applied to all eyes after the surgery.

Postoperatively all patients received ciplox eye drops $0.3 \%$, tear substitutes and topical ascorbate (10\%) four times daily. Drops were tapered and discontinued after 2-3 months.

\section{Statistical analysis}

The preoperative and postoperative data were analyzed by $\chi^{2}$ test with the help of Statistical Package for Social Sciences (SPSS) software.

\section{Results}

The demographic and clinical characteristics are summarized in Table 1 and 2.

In all, 10 patients were men $(71.42 \%)$ and four were women $(28.57 \%)$. The average age at the time of surgery was $19.35 \pm 10.91$ years. (range $6-53$ years). The most Common etiological agent was lime (nine eyes). Injury was accidental in most eyes (13 eyes) and most injuries were incurred at home (nine eyes). The mean follow-up after the surgery was $10.14 \pm 4.41$ months (range 4-15 months). Amniotic membrane transplantation was performed within 3 weeks $(9.93 \pm 3.8$ days) after the injury (range 3-16 days). Amniotic membrane disintegrated on its own over a period of 7-20 days.

Notably, the pain was dramatically relieved after the AMT in all patients. All the patients were completely free from any pain or discomfort after AMT. Epithelial defects of nine eyes $(60 \%)$ healed within $1-4$ weeks $(15.33 \pm 9.91$ days). Two eyes $(9,13)$ healed between 2 and 2.5 months and four eyes $(1,2,3,10)$ had persistent epithelial defects at the end of 3 months that took another 1 month to heal. The duration of epithelial defect healing was significantly faster in grade II and III burns compared with the group with grade IV burns $\left(P=0.0441, \chi^{2}\right.$ test). None of the patients developed corneal perforation. 
Symblepharon was graded as mild, moderate and severe. Cases with fornix foreshortening and horizontal involvement less than $25 \%$ were graded as mild, 25-50\% involvement as moderate, and greater than this as severe. Symblepharon was seen in nine out of 15 eyes. One eye (4) with Grade II burn developed minimal inferior forniceal shortening. One eye (15) in Grade III burns developed mild symblepharon. In all, 7 out of 8 eyes with grade IV burns developed symblepharon. But symblepharon was mild in most of the cases expect for three eyes $(2,3,12)$ that developed marked conjunctival shortening with ankyloblepharon. All these eyes had acid burns with $100 \%$ conjunctival involvement and total limbal ischaemia. A total of 3 eyes $(5,6,12)$ developed granuloma pyogenicum. All these eyes had Grade IV burns with more than $75 \%$ conjunctival involvement and superior forniceal conjunctival necrosis.

For a follow up period of $10.14 \pm 4.4$ months, improvement in visual acuity was seen in 10 of 15 eyes $(66.66 \%)$. All eyes in Grade II (three eyes) and Grade III (four eyes) showed visual improvement. Whereas in Grade IV burns, of eight eyes only three eyes $(9,10,11)$ had visual improvement, in two eyes $(6,12)$ it remained same, and three eyes $(1,2,3)$ it deteriorated. One eye (2) became PR inaccurate because of development of secondary glaucoma and uveitis.
Superficial corneal vascularization as an indicator of limbal stem cell deficiency was seen in 12 of 15 eyes (80\%). In Grade II burns one eye (15) had 2 clock hours, in grade III burns, two eyes $(5,14)$ showed 3-clock hour of peripheral superficial corneal vascularization. One eye of Grade III burns (13) had 6 clock hour and all eyes of grade IV burns 8-12 clock hour of superficial corneal vascularization encroaching till the center. The severity of corneal vascularization was related to the severity of chemical burn ( $P=0.038, \chi^{2}$ test) (Figures $\left.1-4\right)$.

At the end of 1st and 3rd month post AMT, all patients had stable tear films with none having a value less than $5 \mathrm{~mm}$ on Schirmer's test. Preoperatively all except four eyes $(2,3,9,12)$ had Schirmer's test value more than $5 \mathrm{~mm}$, reflex tearing being the prominent feature seen in most of the eyes.

\section{Discussion}

Amniotic membrane, the outermost portion of foetal membranes possesses anti-inflammatory, ${ }^{13}$ anti scarring, ${ }^{14}$ stem cell proliferating, ${ }^{15}$ and epithelialization promoting effects on the ocular surface. It has been found useful in the treatment of persistent epithelial defect (PED) with ulceration, ${ }^{16}$ primary, and recurrent pterygium with symblepharon, ${ }^{17}$ for conjunctival surface reconstruction ${ }^{18}$ and in combination with limbal grafts in
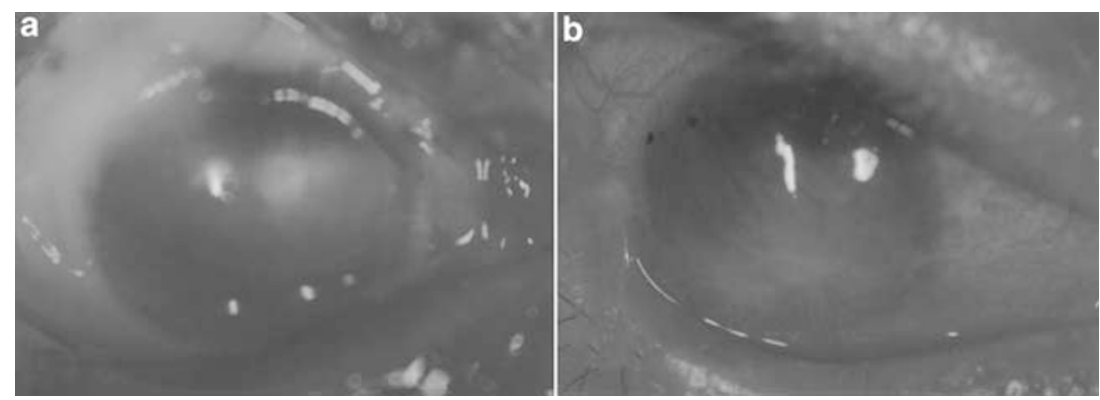

Figure 1 Grade IV lime burn (patient 1). (a) Before surgery, the right eye showed a total corneal epithelial defect with 8 clock hours of LI and 50\% conjunctival involvement. (b) After 4 months of AMT, limbal deficiency with corneal vascularization and inferior symblepharon was noted.
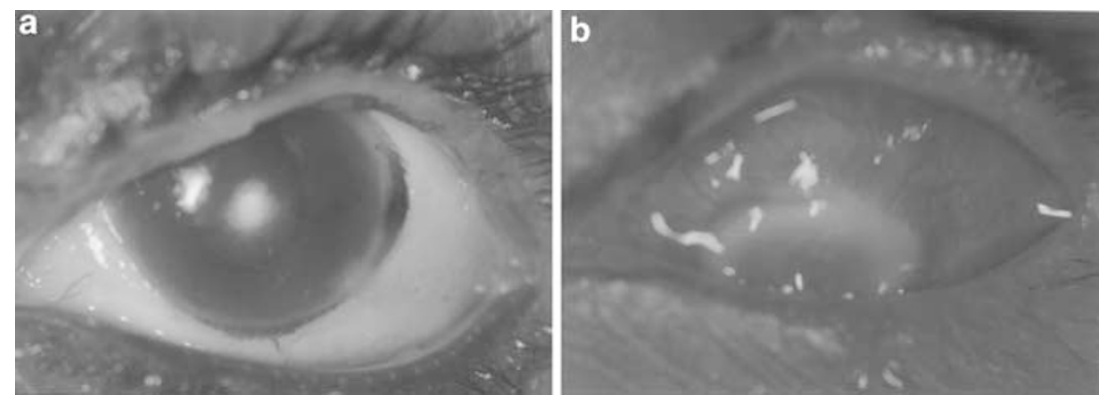

Figure 2 Grade IV acid burn (patient 2). (a) Before surgery, the right eye showed total conjunctival necrosis, 12 clock hour LI and total epithelial defect. (b) After 3 months of AMT total corneal vascularization, symblepharon and PED were noted. 


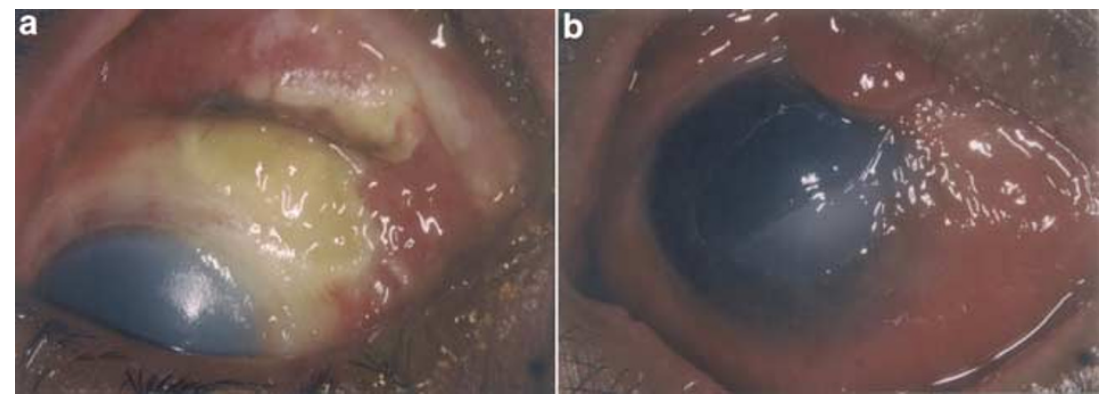

Figure 3 Grade IV lime burn (patient 9). (a) At presentation, right eye had total limbal ischemia, 100\% epithelial defect and superior conjunctival necrosis was noted. (b) After 2 months of AMT granulomas pyogenicum, PED, corneal vascularization, and symblepharon were noted.
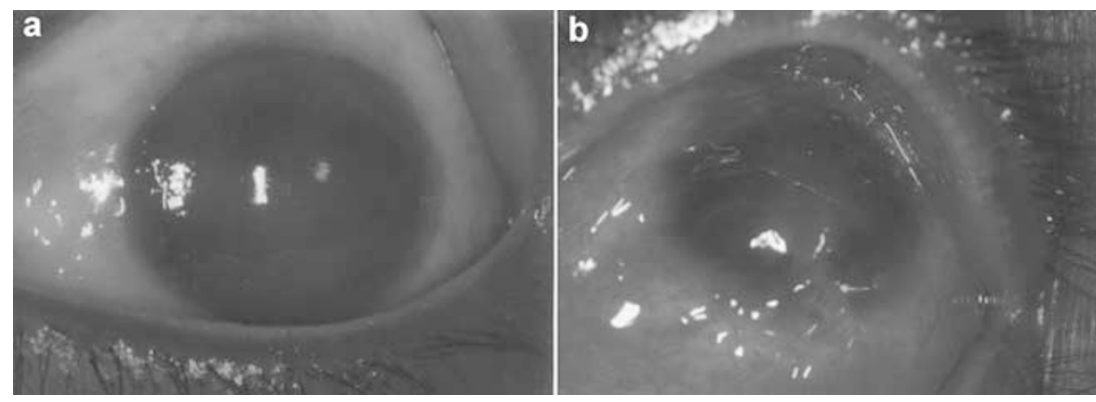

Figure 4 Grade IV lime burn (patient 11). (a) Before surgery total LI with 50\% conjunctival involvement and 100\% epithelial defect were noted. (b) After 4 months of AMT, corneal vascularization was noted.

the reconstruction of ocular surface in advanced ocular cicatricial pemphigoid and Steven-Johnson syndrome ${ }^{19}$ as well as chemical and thermal burns. ${ }^{20}$ Reports regarding the role of AMT in acute ocular burns success are highly variable.

Ocular chemical burns cause extensive limbal and conjunctival cell destruction. But it is conceivable that there remain some conjunctival and corneal stem cells at the basal level, even though flourescein depicts large ocular surface defects. Persistent inflammation with leucocytic infiltration in the acute stage causes further gradual stem cell loss. Persistent inflammation prevents epithelialization and accelerates ulceration and melting with globe perforation. It also contributes to scarring sequelae like symblepharon and lid shortening, tear film deficiency, and inflammatory granuloma in the chronic stage. In addition, in severe burns ischaemic changes result in anterior segment necrosis and sterile corneal ulceration at an early stage after the injury.

It is believed that when used at an early stage, AMT would promote healing of ocular surface by preventing leucocytic infiltration, decreasing the duration and severity of inflammation and protecting the proliferating epithelial stem cell.

Meller $e t a l^{9}$ treated 13 eyes of acute burns with AMT within 2 weeks after the injury. A total of seven eyes had grade II-III burns and six eyes had grade IV burns.

Epithelial defects of all but two patients healed in 2-5 weeks. Only one patient developed a symblepharon. All eyes with grade IV burns experienced limbal stem cell deficiency. Out of five patients with total limbal ischaemia, three required limbal stem cell transplantation, one required large penetrating keratoplasty and conjunctival flap for a corneal perforation, and the last patient had a persistent epithelial defect at the end of 4 months after which he was lost to follow up. AMT alone could not maintain the ocular surface for burns with total limbal ischaemia. Similarly, Dua et $a l^{10}$ reported that in extremely severe burns AMT does not establish the ocular surface or preserve the integrity of the globe.

Kobayashi $e t a l^{11}$ also reported the usefulness of amniotic membrane patch. Burns were mild with less than $1 \backslash 3$ limbal ischaemia in four patients and $1 \backslash 2$ limbal ischaemia in one patient. However, the results of their study cannot in any way suggest the usefulness of AMT in severe burns. A new modification in suture placement for amniotic membrane patch was also suggested.

Running instead of interrupted sutures to anchor the amniotic membrane to the lid margins and episcleral hitching was used. We also devised a new modification for amniotic membrane patching. After spreading the 
amniotic membrane on the ocular surface a symblepharon ring of appropriate size was fitted, and amniotic membrane edges after trimming were sutured to the lid margins. It has the benefit of not only keeping amniotic membrane taut but also there was no need for additional purse string sutures to be placed.

In our study, AM rapidly restored the ocular surface in Grade II burns. Grade II burns, that involve partial stem cell loss usually have a good prognosis with conventional treatments. However, amniotic membrane by virtue of its anti-inflammatory and stem cell proliferating ${ }^{15}$ activity leads to a favourable outcome for long-term ocular surface restoration and visual recovery. AMT was effective to a certain extent in Grade III burns also. AMT promoted epithelialization and none of the eyes had persistent epithelial defects, and improvement in visual acuity was noted in all eyes. None of the eyes developed ulceration or perforation. Although AMT was not totally effective in preventing symblepharon and corneal vascularization, their severity was mild to moderate. The utility of AM in grade IV was found to be highly limited. Symblepharon and corneal vascularization were noted in all eyes. In all, three eyes developed ankyloblepharon and two eyes went into phthisis. It thereby suggested that in severe burns with extensive conjunctival damage it does not completely restore the conjunctival surface and with associated extensive limbal stem cell damage it does not prevent the sequelae of limbal stem cell deficiency. Although stable, a less inflamed external ocular surface was achieved in most of the cases and this may aid in obtaining more successful results when limbal stem cell transplantation is resorted to at a later date.

In conclusion, our experience cautions against the overenthusiasm in the use of amniotic membrane alone in acute chemical burns with extensive limbal ischaemia and conjunctival involvement as the amniotic membrane was not very successful in establishing the ocular surface. It mainly plays an adjunctive role in limbal stem cell deficiency in severe chemical burns with near total limbal ischaemia.

\section{References}

1 Pfister RR, Paterson CA. Ascorbic acid in the treatment of alkali burns of the eye. Ophthalmology 1980; 87: 1050-1057.

2 Pfister RR, Haddox JL, Paterson CA. The efficacy of sodium citrate in the treatment of severe alkali burns of the eye is influenced by the route of administration. Cornea 1982; 1: 205-211.

3 Seedor JA, Perry HD, McNamara TF, Golub LM, Buxton DF, Guthrie DS. Systemic tetracycline treatment of alkali- induced corneal ulceration in rabbits. Arch Ophthalmol 1987; 105: 268-271.

4 Donshik PC, Berman MB, Dohlman CH, Gage J, Rose J. Effect of topical corticosteroids on ulceration in alkaliburned corneas. Arch Ophthalmol 1978; 96: 2117-2120.

5 Kenyon KR, Berman M, Rose J, Gage J. Prevention of stromal ulceration in the alkali-burned rabbit corneas by glued on contact lens. Evidence for the role of polymorphonuclear leukocytes in collagen degradation. Invest Ophthalmol Vis Sci 1979; 18: 570-587.

6 Reim M, Overkamping B, Kuckelhorn R. 2 years experience with tenoplasty. Ophthalmol 1992; 89: 824-830.

7 Fogle JA, Kenyon KR, Foster CS. Tissue adhesive arrests stromal melting in the human cornea. Am J Ophthalmol 1980; 89: 795-802.

8 Red Brake C, Buchal V, Reim M. Keratoplasty with a scleral rim after most severe eye burns. Klin Monatsbl Augenheilkd. 1996; 208: 145-151.

9 Mellor D, Pires RTF, Mack RJS, Figueiredo F, Heiligenhaus A, Park WC et al. Amniotic membrane transplantation for acute chemical and thermal burns. Ophthalmology 2000; 107: 980-990.

10 Joseph A, Dua HS, King AJ. Failure of amniotic membrane transplantation in the treatment of acute ocular burns. $\mathrm{Br} J$ Ophthalmol 2001; 85: 1065-1069.

11 Kobayashi A, Shirao Y, Yoshita T, Yagami K, Segawa Y, Kawasaki $\mathrm{K}$ et al. Temporary amniotic membrane patching for acute chemical burns. Eye 2003; 17: 140-158.

12 Roper-Hall MJ. Thermal and chemical burns. Trans Ophthalmol Soc UK 1965; 85: 631-640.

13 Choi YS, Kim JY, Wee WR, Lee JH. Effect of application of human amniotic membrane in rabbit corneal wound healing after excimer laser photo refractive keratectomy. Cornea 1998; 17: 389-395.

14 Tseng SC, Li D-Q, Ma X. Suppression of transforming growth factor-beta isoforms, TGF-beta receptor type II, and myofibroblast differentiation in cultured human corneal and limbal fibroblast by amniotic membrane matrix. J Cell Physiol 1999; 179: 325-335.

15 Tseng SCG, Prabhasawat P, Barton K, Gray T, Melter D. Amniotic membrane transplantation with or without limbal allografts for corneal surface reconstruction in patients with limbal stem cell deficiency. Arch Ophthalmol 1998; 116: 431441.

16 Lee SH, Tseng SCG. Amniotic membrane transplantation for persistent epithelial defects with ulceration. Am J Ophthalmol 1997; 123: 303-312.

17 Shimazaki J, Shinozaki N, Tsubota K. Transplantation of amniotic membrane and limbal autograft for patients with recurrent pterygium associated with symblepharon. $\mathrm{Br} \mathrm{J}$ Ophthalmol. 1998; 82: 235-240.

18 Tseng SCG, Prabhasawat P, Lee SH. Amniotic membrane transplantation for conjunctival surface reconstruction. Am J Ophthalmol 1997; 124: 765-774.

19 Tsuobota K, Satake Y, Ohyama M, Tuda I, Takano Y, Ono M et al. Surgical reconstruction of the ocular surface in advanced ocular cicatricial pemphigoid and Steven-Johnson syndrome. Am J Ophthalmol 1996; 122: 38-52.

20 Shimazaki J, Yang HY, Tsuobota K. Amniotic membrane transplantation for ocular surface reconstruction in patients with chemical and thermal burns. Ophthalmology 1997; 104: 2068-2076. 